\title{
sensors
}

ISSN 1424-8220

(C) 2008 by MDPI

www.mdpi.org/sensors

Review

\section{Conductometric Microbiosensors for Environmental Monitoring}

\author{
Nicole Jaffrezic-Renault ${ }^{1, *}$ and Sergei V. Dzyadevych ${ }^{2}$ \\ 1 Universite de Lyon, Laboratory of Analytical Sciences, UMR CNRS 5180, Universite Claude \\ Bernard Lyon 1, 43 Boulevard 11 Novembre 1918, 69622 Villeurbanne Cedex, France \\ 2 Laboratory of Biomolecular Electronics, Institute of Molecular Biology and Genetics, National \\ Academy of Sciences of Ukraine, 150 Zabolotnogo St., Kiev 03143, Ukraine \\ * Author to whom correspondence should be addressed; E-mail: nicole.jaffrezic@ univ-lyon1.fr; \\ Tel. +33472431182; Fax: +33472431206
}

Received: 7 March 2008 / Accepted: 9 April 2008 / Published: 11 April 2008

\begin{abstract}
This review presents the principles of conductometric measurements in ionic media and the equivalent electrical circuits of different designs for conductometric measurements. These types of measurements were first applied for monitoring biocatalytic reactions. The use of conductometric microtransducers is then presented and detailed in the case of pollutant detection for environmental monitoring. Conductometric biosensors have advantages over other types of transducers: they can be produced through inexpensive thinfilm standard technology, no reference electrode is needed and differential mode measurements allow cancellation of a lot of interferences. The specifications obtained for the detection of different pesticides, herbicides and heavy metal ions, based on enzyme inhibition, are presented as well as those obtained for the detection of formaldehyde, 4chlorophenol, nitrate and proteins as markers of dissolved organic carbon based on enzymatic microbiosensors.
\end{abstract}

Keywords: Interdigitated microelectrodes, conductometric measurements, enzymatic microsensors, whole-cell microsensors, pesticides, herbicides, TOC, nitrate, heavy metals, toxicity assessment. 


\section{Introduction}

Intensive industrialization and the use of chemicals in agriculture have contributed to the build up of many toxic compounds in air, soil, and water, which cause environmental pollution [1]. The analysis of these toxic compounds in environmental matrices depends generally on two concepts. In the first, the pollutants are identified and quantified by classical analytical techniques such as gas chromatography (GC/MS) or high performance liquid chromatography (HPLC/MS). These techniques are timeconsuming because of sample preparation and need for pre-concentration, expensive, and, in case of water samples, cannot be performed easily outside the laboratory. In addition, sometimes they are restricted to a limited set of substances. The selection of target compounds may completely fail to recognize the most harmful toxic constituents, coming from, for example, degradation processes. In the second concept, the compounds are not clearly identified, but measurements allow the assessment of toxicity of the tested samples. These techniques are very useful for assessing the potential risk of contaminated water samples. A variety of toxicity measurement systems exist, including those based on bacteria and algae, animal cells, small mammals, fish fly, and zooplankton. Some of these systems, e.g., animals and fish larvae, are difficult to handle and they do not provide a rapid response. Also, use of some of these systems may be ethically objectionable. Other systems, such as mammalian cells are expensive and results are not always consistent. In addition, the response of single toxicity assay is an insufficient measure of adverse biological impact of a compound in a generally diverse receiving ecosystem. Different toxicants act differently and not all life forms are equally susceptible. Consequently, several different assays need to be used simultaneously to assess the toxicity adequately [2].

The analysis of various biological and chemical pollutants in environmental matrices has entered in a new phase during the last decade. Improvements in instrumentation, sampling, and sample preparation techniques have become essential to keep-up with the requirements of detection at low levels as ppb or ppt range, as well as to achieve a faster analysis. The creation of electrochemical biosensors is probably one of the most promising ways to solve some problems concerning sensitive, fast and cheap analytical techniques.

A biosensor converts the modification of the physical or chemical properties of a biomatrix, which occurs as a result of biochemical interactions, into an electric or an optic signal whose amplitude depends on the concentration of defined analytes in the solution. Functionally, the device consists of two parts: a biomatrix, i.e. a detecting layer of immobilised material (enzymes, antibodies, receptors, organelles, microorganisms), and a transducer (potentiometric, impedimetric, amperometric, conductometric, acoustic, optic or colorimetric...).

However, compared to amperometric and potentiometric biosensors, little work has been devoted to conductometric enzyme biosensors based on thin-film interdigitated electrodes [3-6]. The conductometric biosensors are based on the fact that almost all enzymatic reactions involve either consumption or production of charged species and, therefore, lead to a global change in the ionic composition of the tested sample [7]. Biosensors based on the conductometric principle present a number of advantages: a) thin-film electrodes are suitable for miniaturisation and large scale production using inexpensive technology, b) they do not require any reference electrode, c) transducers are not light sensitive, d) the driving voltage can be sufficiently low to decrease significantly the power 
consumption, e) large spectrum of compounds of different nature can be determined on the basis of various reactions and mechanisms.

The liquids analysed are mostly considered to have significant background conductivity, which is easily modified by different factors, therefore the selectivity of this method is presumed to be low and consequently its potential use for different application - rather doubtful [8]. However, in the case of an integrated microbiosensor, most of these difficulties can be overcome using a differential measuring scheme which compensates for changes in background conductivity, the influence of temperature variations and of other factors $[9,10]$.

This review describes basic theoretical principles of conductometry in bioanalytical practice and application of conductometric biosensors for environmental monitoring.

\section{Conductometric measurement methods}

The conductivity of liquids results from the dissociation of the dissolved substance, an electrolyte, into ions and the migration of the latter induced by an electrical field. When a potential difference is applied to the electrode, there is an electrical field within the electrolyte, so the chaotic ion movement is influenced by the ordered, oppositely directed movement of ions (those with negative charge more towards anodes, while positively charged ones move towards cathodes) (Figure 1). Thus, the current in the electrolyte is caused by the ion movement towards the electrodes where the ions are neutralized and isolated as neutral atoms (or molecules).

Figure 1. Ion migration in the solution volume and electrolyte conductivity.

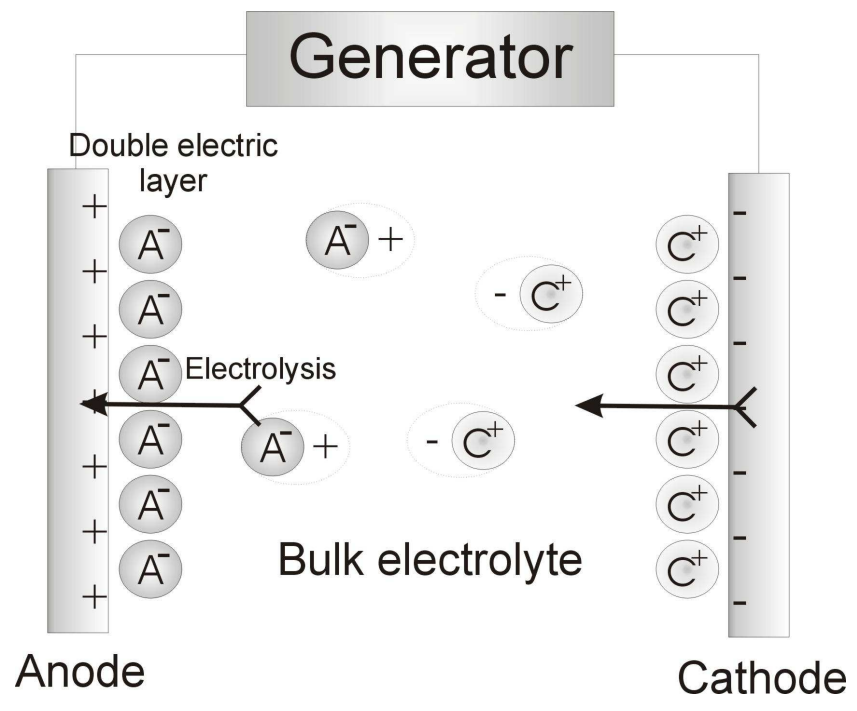

The ion flux, i.e. the number of ions passing through a unit of electrolyte cross-section per unit of time $\left(\mathrm{p}_{\mathrm{i}}\right)$ can be determined by the formula:

$$
p_{i}=c_{i} v-k_{i} c_{i} \operatorname{grad} \mu_{i}-z_{i} v_{i} c_{i} F \operatorname{grad} \psi
$$


where $\mathrm{v}$ - speed of solution flow due to natural or forced convection; $\mathrm{c}_{\mathrm{i}}$ - ion concentration; $\mathrm{k}_{\mathrm{i}}-$ diffusion coefficient; $z_{i}$ - charge number; $v_{i}$ - speed of ion movement caused by applied field; F Faraday number; $\psi$ electrical potential; $\mu$ electrochemical potential..

Thus, the first member in formula (1) corresponds to the contribution of the convectional flow of ions at a concentration of $c_{i}$; the second - the contribution of their molecular diffusion; the third - that of the ion migration induced by the applied potential. Temperature, as a rule, is assumed to be constant ( $\mathrm{T}=$ const, $\operatorname{grad} \mathrm{T}=0$ ), so the ion's thermal diffusion can be ignored.

In reality all three processes usually coexist, but present an initial influence on each other. In any case some assumptions can be made so that only one of them is taken into account. Thus, in the case of homogenous immobile electrolyte the first and second members of equation (1) can be neglected, and only the ion migration caused by the electric field effect can be considered. Then

$$
\mathrm{p}_{\mathrm{i}}=-\mathrm{z}_{\mathrm{i}} \mathrm{v}_{\mathrm{i}} \mathrm{c}_{\mathrm{i}} \mathrm{F} \operatorname{grad} \psi=-\mathrm{c}_{\mathrm{i}} \mathrm{u}_{\mathrm{i}} \operatorname{grad} \psi
$$

where $v_{i}$ - speed of ion movement, $c_{i}$ - ion concentration, $u_{i}=z_{i} v_{i} F-$ ion mobility which is a constant value for the given ion in the infinitely diluted solution. In Table 1 the values of mobility of some ions for an infinite dilution in aqueous solutions at a temperature of $25^{\circ} \mathrm{C}$ are shown.

The current density, i.e. the current per unit of the system cross-section is an algebraic sum of products of ion fluxes and ion charges:

$$
\mathrm{j}=\mathrm{F} \sum \mathrm{z}_{\mathrm{i}} \mathrm{p}_{\mathrm{i}}=\mathrm{F} \operatorname{grad} \psi \sum \mathrm{z}_{\mathrm{i}} \mathrm{c}_{\mathrm{i}} \mathrm{u}_{\mathrm{i}}
$$

On the other hand, according to Ohm's law

$$
\mathrm{j}=\mathrm{S} \operatorname{grad} \psi
$$

where $S$ - conductivity, i.e. reciprocal value to resistance.

Hence, from (3) and (4):

$$
\mathrm{S}=\mathrm{F} \sum \mathrm{z}_{\mathrm{i}} \mathrm{c}_{\mathrm{i}} \mathrm{u}_{\mathrm{i}}
$$

Thus, the conductivity of the electrolyte solution depends on the ion concentration and mobility. The resistance of electrolyte solution is well-known to be in direct proportion to the distance "L" between the immersed electrodes and reciprocal to their area A, therefore:

$$
\mathrm{S}=\chi \times(\mathrm{A} / \mathrm{L})
$$

where $\chi$ - specific conductivity. 
Table 1. Ion mobility in infinitely diluted aqueous solutions at temperature of $25^{\circ} \mathrm{C}$.

\begin{tabular}{|c|c|c|c|}
\hline Cation & $\mathrm{S}, \mathrm{Ohm}^{-1} \mathrm{~cm}^{2}$ & Anion & $\mathrm{S}, \mathrm{Ohm}^{-1} \mathrm{~cm}^{2}$ \\
\hline $\mathrm{H}^{+}$ & 349.8 & $\mathrm{OH}^{-}$ & 198.3 \\
\hline $\mathrm{Co}\left(\mathrm{NH}_{3}\right)_{6}{ }^{3+}$ & 102.3 & $\mathrm{C}_{2} \mathrm{O}_{4}{ }^{2-}$ & 111.0 \\
\hline $\mathrm{NH}_{4}^{+}$ & 73.6 & {$\left[\mathrm{Fe}(\mathrm{CN})_{6}\right]^{4-}$} & 110.5 \\
\hline $\mathrm{K}^{+}$ & 73.5 & {$\left[\mathrm{Fe}(\mathrm{CN})_{6}\right]^{3-}$} & 100.9 \\
\hline $\mathrm{Pb}^{2+}$ & 70.0 & {$\left[\mathrm{Co}(\mathrm{CN})_{6}\right]^{3-}$} & 98.9 \\
\hline $\mathrm{La}^{3+}$ & 69.7 & $\mathrm{CrO}_{4}^{2-}$ & 85.0 \\
\hline $\mathrm{Fe}^{3+}$ & 68.0 & $\mathrm{SO}_{4}^{-}$ & 80.0 \\
\hline $\mathrm{Ba}^{2+}$ & 63.6 & $\mathrm{I}^{-}$ & 78.8 \\
\hline $\mathrm{Al}^{3+}$ & 63.0 & $\mathrm{Br}^{-}$ & 78.1 \\
\hline $\mathrm{Ag}^{+}$ & 61.9 & $\mathrm{CN}^{-}$ & 78.0 \\
\hline $\mathrm{Ca}^{2+}$ & 59.5 & $\mathrm{Cl}^{-}$ & 76.4 \\
\hline $\mathrm{Sr}^{2+}$ & 59,5 & $\mathrm{NO}_{3}^{-}$ & 71,5 \\
\hline $\mathrm{CH}_{3} \mathrm{NH}_{3}^{+}$ & 58.7 & $\mathrm{C}_{2} \mathrm{O}_{4}{ }^{2-}$ & 74.2 \\
\hline $\mathrm{Cu}^{2+}$ & 56.6 & $\mathrm{CO}_{3}^{2-}$ & 69.3 \\
\hline $\mathrm{Zn}^{2+}$ & 56.6 & $\mathrm{ClO}_{4}^{-}$ & 67.3 \\
\hline $\mathrm{Cd}^{2+}$ & 54.0 & $\mathrm{ClO}_{3}{ }^{-}$ & 65.0 \\
\hline $\mathrm{Fe}^{2+}$ & 53.5 & $\mathrm{O}_{4}^{2-}$ & 57.0 \\
\hline $\mathrm{Mn}^{2+}$ & 53.5 & $\mathrm{~F}^{-}$ & 55.4 \\
\hline $\mathrm{Mg}^{2+}$ & 53.1 & $\mathrm{CHOO}^{-}$ & 54.6 \\
\hline $\mathrm{Co}^{2+}$ & 52.8 & $\mathrm{HCO}_{3}^{-}$ & 44.5 \\
\hline$\left(\mathrm{CH}_{3}\right)_{2} \mathrm{NH}_{2}{ }^{+}$ & 51.9 & $\mathrm{CH}_{3} \mathrm{CO}_{2}^{-}$ & 40.9 \\
\hline $\mathrm{Na}^{+}$ & 50.1 & $\mathrm{HC}_{2} \mathrm{O}_{4}^{-}$ & 40.2 \\
\hline$\left(\mathrm{CH}_{3}\right)_{3} \mathrm{NH}^{+}$ & 47.3 & $\mathrm{H}_{2} \mathrm{PO}_{4}^{-}$ & 36.0 \\
\hline \multirow[t]{3}{*}{$\mathrm{Li}^{+}$} & 38.7 & $\mathrm{C}_{2} \mathrm{H}_{5} \mathrm{CO}_{2}^{-}$ & 35.8 \\
\hline & & $\mathrm{C}_{3} \mathrm{H}_{7} \mathrm{CO}_{2}^{-}$ & 32.6 \\
\hline & & $\mathrm{C}_{6} \mathrm{H}_{5} \mathrm{CO}_{2}^{-}$ & 32.4 \\
\hline
\end{tabular}

This leads to the following conclusions: conductometric measurement commonly consists of determining the conductivity of a solution between two parallel electrodes; its value is a sum of all the ions within the solution tested.

\section{Transducers for conductometric biosensors}

The conductometric transducer is a miniature two-electrode device designed to measure the conductivity of the thin electrolyte layer adjacent to the electrode surface. Most authors agree that the best design for the development of conductometric electrodes is an interdigitated structure [11-17].

The physical-chemical processes in the electrochemical cell with a conductometric interdigitated transducer are mostly simulated by equivalent schemes like those shown in Figures 2 and 3 [11-15]. In our case the $C_{d l}$ is double layer capacity, independent of current frequency; $R_{p}$ is penetration resistance 
simulating chemical polarisation and, like $\mathrm{C}_{\mathrm{dl}}$, independent of current frequency; $\mathrm{Z}_{\mathrm{w}}$ is diffusion impedance simulating concentration polarisation and depending on current frequency; $\mathrm{R}_{\text {sol }}$ is electrolyte resistance.

Figure 2. Classical equivalent circuit (a) and corresponding impedance curve (b) for a metal-electrolyte interface. $R_{S}$ is the real part of impedance and $X_{S}$ is the imaginary part.

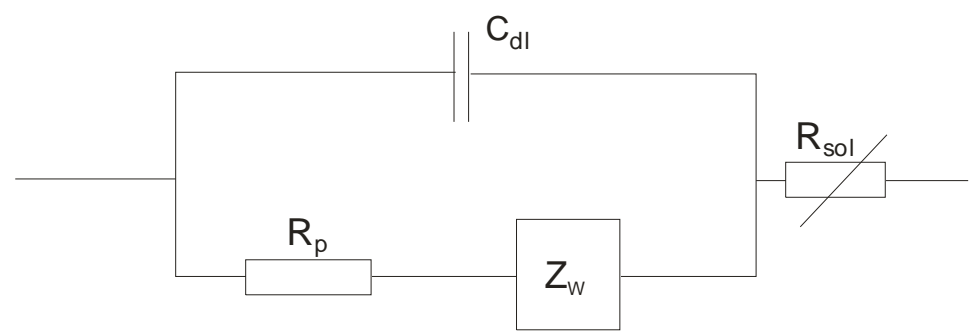

a

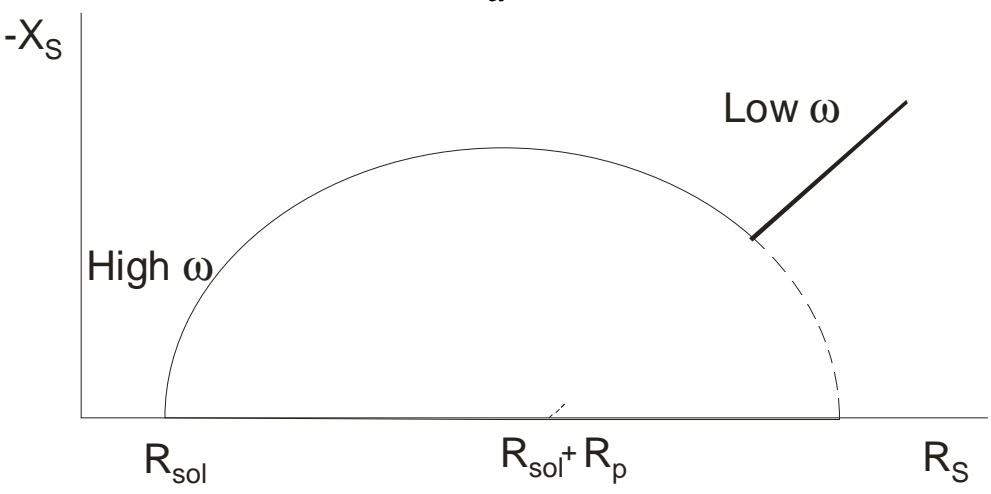

b

Figure 3. Equivalent circuit (a) and corresponding impedance curve (b) for a metalelectrolyte interface with additional oxide capacity. $R_{S}$ is the real part of impedance and $\mathrm{X}_{\mathrm{S}}$ is the imaginary part.

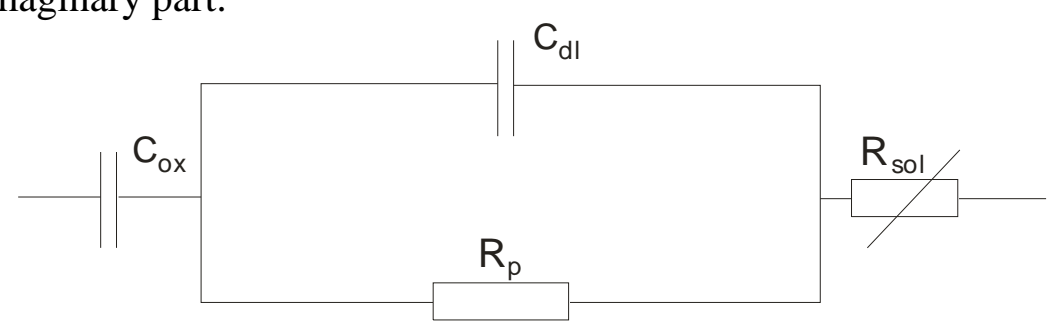

a

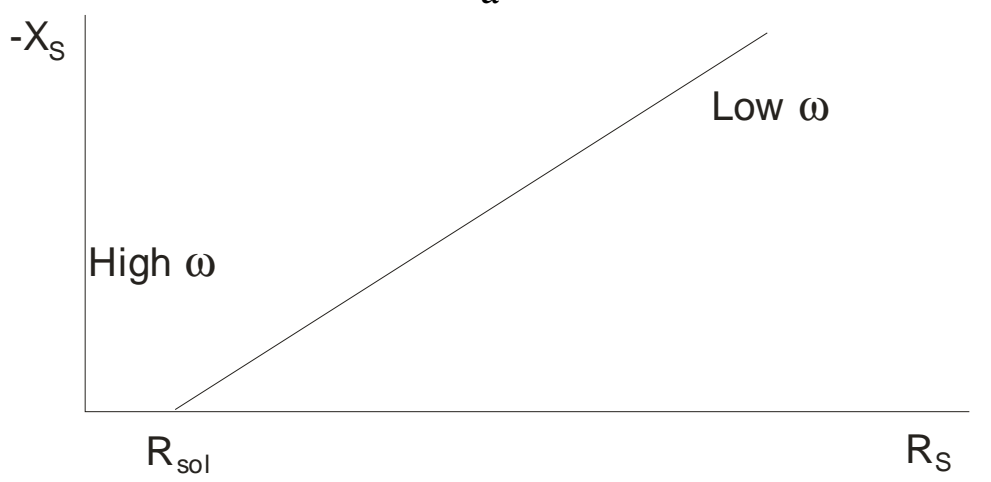


The theoretical calculation of these circuits has been presented in Ref.11. For the first case (Figure 2), i.e. in the absence of oxide capacitance:

$$
\begin{aligned}
& \mathrm{R}_{\mathrm{s}}=\mathrm{R}_{\mathrm{sol}}+\left[\mathrm{R}_{\mathrm{p}} /\left(1+\omega^{2} \mathrm{C}_{\mathrm{dl}}^{2} \mathrm{R}_{\mathrm{p}}^{2}\right)\right] \\
& \mathrm{X}_{\mathrm{s}}=-\left[\left(\omega \mathrm{C}_{\mathrm{dl}} \mathrm{R}_{\mathrm{p}}^{2}\right) /\left(1+\omega^{2} \mathrm{C}_{\mathrm{dl}}^{2} \mathrm{R}_{\mathrm{p}}^{2}\right)\right]
\end{aligned}
$$

In the second case (Figure 3), i.e. when the oxide capacity is present

$$
\begin{aligned}
& \mathrm{R}_{\mathrm{s}}=\mathrm{R}_{\mathrm{sol}}+\mathrm{R}_{\mathrm{p}} /\left(1+\omega^{2} \mathrm{C}_{\mathrm{dl}}{ }^{2} \mathrm{R}_{\mathrm{p}}{ }^{2}\right) \\
& \mathrm{Xs}=\left[1+\omega \mathrm{C}_{\mathrm{dl}} \mathrm{R}_{\mathrm{p}}^{2}\left(\mathrm{C}_{\mathrm{dl}}+\mathrm{C}_{\mathrm{ox}}\right)\right] /\left[\mathrm{C}_{\mathrm{ox}}\left(1+\omega^{2} \mathrm{C}_{\mathrm{dl}}^{2} \mathrm{R}_{\mathrm{p}}^{2}\right)\right]
\end{aligned}
$$

The impedance curves obtained in accordance with (7), (8) are presented in Figure 4, as well as the changes in curve shape brought by variations of different circuit parameters. As it can be seen, all circuit components (except for $\mathrm{C}_{\mathrm{dl}}$ ) influence essentially the curve shapes at low frequency while at high frequency only a change in $\mathrm{R}_{\text {sol }}$ causes the displacement of the impedance curve, i.e. changes in the real impedance component - conductivity.

Figure 4. Theoretical impedance curves for the model of a conductometric cell. Frequency varied from $100 \mathrm{~Hz}$ up to $200 \mathrm{kHz}$. The chosen circuit parameters:

1. $\mathrm{R}_{\mathrm{p}}=5 \mathrm{\kappa Ohm}, \mathrm{R}_{\mathrm{sol}}=1 \kappa \mathrm{Khm}, \mathrm{C}_{\mathrm{dl}}=5 \mathrm{nF}$,

2. $\mathrm{R}_{\mathrm{p}}=10 \kappa \mathrm{Ohm}, \mathrm{R}_{\mathrm{sol}}=1 \kappa \mathrm{Khm}, \mathrm{C}_{\mathrm{dl}}=50 \mathrm{nF}$,

3. $\mathrm{R}_{\mathrm{p}}=10 \kappa \mathrm{Ohm}, \mathrm{R}_{\mathrm{sol}}=1 \kappa \mathrm{Khm}, \mathrm{C}_{\mathrm{dl}}=5 \mathrm{nF}, \mathrm{C}_{\mathrm{ox}}=1000 \mu \mathrm{F}$,

4. $\mathrm{R}_{\mathrm{p}}=10 \mathrm{\kappa Ohm}, \mathrm{R}_{\mathrm{sol}}=1 \mathrm{\kappa Ohm}, \mathrm{C}_{\mathrm{dl}}=5 \mathrm{nF}, \mathrm{C}_{\mathrm{ox}}=1000 \mu \mathrm{F}$,

5. $\mathrm{R}_{\mathrm{p}}=10 \kappa \mathrm{\kappa hm}, \mathrm{R}_{\mathrm{sol}}=1 \kappa \mathrm{\kappa hm}, \mathrm{C}_{\mathrm{dl}}=5 \mathrm{nF}, \mathrm{C}_{\mathrm{ox}}=100 \mu \mathrm{F}$,

6. $\mathrm{R}_{\mathrm{p}}=10 \kappa \mathrm{Ohm}, \mathrm{R}_{\mathrm{sol}}=1 \kappa \mathrm{Ohm}, \mathrm{C}_{\mathrm{dl}}=5 \mathrm{nF}, \mathrm{C}_{\mathrm{ox}}=10 \mu \mathrm{F}$

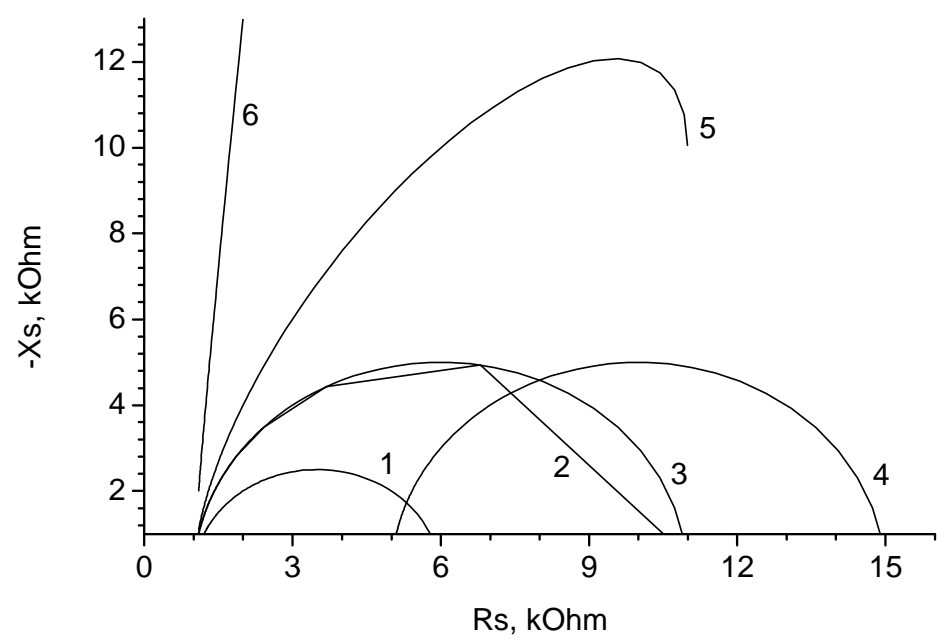


As mentioned above, an enzyme reaction is followed by a change in the solution's conductivity in the vicinity of the electrode, which is recorded by the conductometric transducer. This change can be simulated by the change of background conductivity which in our experiments was realized by varying the $\mathrm{KCl}$ concentration in solution and its temperature $[11,13,14,16,17]$. The change in solution background conductivity has been shown to affect mainly the high-frequency part of admittance. Therefore, the transducer is more sensitive at high frequency. Besides, under these experimental conditions the main contribution to the signal is provided by the real admittance component, conductivity, which is necessary for a conductometric biosensor. Similarly the admittance was affected by changes in solution temperature. At frequencies higher than $10 \mathrm{kHz}$ the electrochemical impedance has been shown to be mainly determined by the volume properties of the phases in $\operatorname{contact}^{14}$, so conductometric transducers can be used for the development of enzyme biosensors. The surface effects at the electrodes and their degradation during storage can be neglected.

One important aspect in the development of conductometric interdigital transducers is the proper selection of electrode material. Various materials have been tested: platinum [5, 15-22], gold [5, 11, 14, 18, 23-25], aluminium [11, 14, 26], nickel [11, 14, 26], copper [11, 14, 21], titanium [5, 11, 14], chromium [11, 14], $\mathrm{Ta}_{2} \mathrm{O}_{5}[12,13]$, silver [22] and carbon [27]. In general, all these materials are suitable, especially when high-frequency ac is used. However, the electrodes made of precious metals have better characteristics. Titanium, chromium and aluminium electrodes have been revealed to be undesirable for operation with biological liquids since these electrodes have low sensitivity to changes in the ion strength of solution and reach conductivity saturation in a short time.

Concerning the dimensional characteristics of electrodes, the investigations of the authors and the data presented in $[16,18]$ show that transducer miniaturization does not require the number of electrode fingers to be increased by a corresponding decrease in their size, as was earlier thought. On the contrary, doing so resulted in lower transducer sensitivity. Miniaturization should be performed by decreasing both the electrode working surface and its characteristic dimensions. On the other hand, an electrode with large fingers is not an appropriate design (though transducer sensitivity can be higher) because in this case the thickness of the biologically active membrane plays a significant role. The main parameter to determine sensor size is the correlation between membrane thickness, the electrode characteristic dimensions and its active area.

Conductometric transducers are mostly manufactured by microelectronics techniques photolithography and vacuum spraying - whose advantages are described in detail in [28]. Some authors have used thick-film printing technology [22, 29], whose merits are reviewed in [28]. All authors, however, agree that it is much easier to produce conductometric transducers than electrochemical transducers of other type.

\section{Conductometry in enzyme catalysis}

The conductometric measuring method can be used in enzyme catalysis to determine substance concentration and enzyme activity, selectivity in this case being provided just by the enzymes which catalyze only defined reactions. As a matter of fact, the subject under consideration is not a biosensor as such but an application of this method in enzymology. 
In 1961 one of the first research efforts in this field was published, showing how it might be possible to determine urea concentration in solutions [30]. This method is based on the difference between electric conductivity of a urea solution and that of a solution of ammonium carbonate formed as a result of urea hydrolysis by urease. In the experiments a bridge-measuring scheme was used. The urease activity was shown to decrease in the presence of heavy metal (Ag, $\mathrm{Hg}$, etc.) ions in the solution. Such electrolytes as $\mathrm{NaCl}$ or $\mathrm{KCl}$ do not influence urease activity, but if their concentration in the solution is high it can lead to a wrong result, especially at low urea concentrations. At low electrolyte concentrations in experiments without a buffer solution, during urea hydrolysis the medium $\mathrm{pH}$ gradually changed from 7 to 9 . However, this caused only an insignificant change in the urease activity while the solution conductivity during the reaction varied substantially. The urea concentration was determined within the $0.1 \mu \mathrm{M}-2 \mathrm{mM}$ range, at optimal $\mathrm{pH}$ 7. A comparison of the conductometric method with other methods of urea analysis carried out in that work has shown that the first is characterized by its high accuracy, speed and simplicity. Besides, in contrast to optical methods, the measurement accuracy of conductometry does not depend on solution colour.

In 1965 a paper was published on applying the conductometric method to the study of the kinetics of urea enzyme hydrolysis as well as to urease activity determination [31]. A differential measuring scheme was used in these experiments. The system consisted of two pairs of platinum plates, each of them placed in its own measuring cell, one with the enzyme, another without. The difference between signals from both cells was registered, thus eliminating any error associated with variations of the parameters outside the cells (temperature, buffer concentration, etc.). The determination range of urea concentration was $1-75 \mathrm{mM}$, while that of urease activity was $0.04-2.5$ activity units/ml. Comparing the data obtained with the results of classical photometric analysis showed that the conductometric method has all the merits of the classical one, and exceeds the latter in accuracy and speed.

At the same time in [32] research was presented demonstrating that the changes in conductivity during an enzyme reaction can be considered to be a universal characteristic of the substrate chemical transformation. Even if the conductivity of the products of the reaction and that of the substrate differs a little, the change in the solution viscosity and in the level of hydration of molecules and ions at the substrate transformation (especially in the presence of other current carriers in the solution) cause noticeable variation in the tested mixture. To prove experimentally the potential of conductometry, the authors chose reactions associated with different mechanisms of conductivity change. It was important to expose the character of conductivity change in the case of evident changes in the solution composition as well as when only solution viscosity and level of molecule hydration vary as a result of the reaction. The enzyme hydrolysis of acetylcholine and starch, on the one hand, and the enzyme depolymerization of gialuronate, on the other, were considered to be the reactions meeting these requirements.

Acetylcholine hydrolysis is accompanied by the rupture of the ester bond and the formation of acetic acid dissociated into protons and $\mathrm{CH}_{3} \mathrm{COO}^{-}$. Protons do not participate in the total conductivity mechanism because the reaction takes place in a phosphate buffer, $\mathrm{pH} 7.8$, while the appearance of $\mathrm{CH}_{3} \mathrm{COO}^{-}$anions in the solution results in an increase of the solution conductivity.

For starch hydrolysis, filtered human saliva was added to the starch solution to decrease the solution viscosity and increase the level of starch hydrolysis and so increase the solution conductivity. When 
gialuronidase was used, the conductivity increased as a result of reducing the viscosity of the solution due to the depolymerization of the gialuronate molecules.

The authors have demonstrated that the conductometric method is preferable to the well-known routine methods of biochemical analysis because of its higher accuracy and lower labour consumption. Using a single device and a single method with no modifications, the kinetics of three enzyme processes with specific features were studied, while three devices based on different principles would be required for classical enzyme analysis. In the next work the authors modified their conductometric device and used a differential mode to measure the activities of collagenase, trypsin, lactate dehydrogenase and pseudocholinesterase [33].

However, despite demonstrating the potential of the conductometric method to record enzyme processes, the character of all the works mentioned is that of a preliminary or feasibility study.

At the beginning of the $80 \mathrm{~s}$ a detailed analysis concerning the potentials and limitations of the conductometric method of measurement was performed for the complex study of urease [34]. In the first part of the work, the effect on the conductivity of the medium $\mathrm{pH}$, the urea, urease and salt concentrations of the studied solution was investigated in the absence of any enzyme reaction. It was shown that the changes in concentrations of the solution compounds cause no substantial variations of its conductivity which is why these changes can be neglected. The curve of conductivity-pH dependence is bell-shaped with a maximum at $\mathrm{pH} 8.0$ for Tris-buffer and at $\mathrm{pH} 6.0$ for a citrate buffer.

In the second part of the work the influence of the medium conditions mentioned on urea hydrolysis was investigated. Though $\mathrm{pH} 7.2$ was shown to be optimal for urease in citrate buffer, the substantial dependence of the reaction speed on the solution ion strength was revealed at this value - the speed decreased with rising ion strength, while at pH 6.5 it hardly changed. The Michaelis constant for urease in citrate buffer, $\mathrm{pH} 4.5$, was determined to be around $2.5 \mathrm{mM}$. The linear dependence of the speed of the enzyme reaction on the urease concentration in the solution was also obtained. The successful use of the conductometric method to study the activity of urease, described in this work, can be considered as a convincing argument for its potential due to high sensitivity and good agreement of the kinetic parameters obtained by the conductometric method compared with the results of classical biochemical analysis.

In $[7,35]$ a 6-channel conductometer is used to study different enzymes. The investigation allowed the authors to formulate five factors that bring about, separately or in combination with each other, a change in conductivity, thus ensuring the potential of the conductometric method to record parameters during enzyme reactions (Table 2). In some reactions several factors work simultaneously, namely factors 3 and 5 , in reactions with phosphorilase, factors 1, 3-5, in those with apirase. Factors 1 and 2 influence the conductivity in the most effective way and consequently are the most promising when using conductometry in enzymology. The decrease in size of charged particles does not cause considerable change in conductivity (phosphatase substrates). In the reactions with proton migration some influence of the buffer type has to be taken into account as an additional factor - an anion buffer decreases conductivity while a cation one increases it due to protoning. Therefore, the choice of the type of buffer is very important. Experiments demonstrated a considerable increase in conductivity in Tris and imidasole buffers in reactions with lipase, and an insignificant change in conductivity of these enzymes in phosphate buffer. The conductometric method was also shown to be promising in all the 
reactions causing a change in $\mathrm{pH}$, which is determined as a rule by $\mathrm{pH}$-titration. The sensitivities of both methods are comparable, but conductometry is preferable due to its lower cost and simplicity of use, besides; titration (unlike conductometry) can be performed only in the direction of $\mathrm{pH}$ change and requires more complicated manipulation at operation.

Table 2. Factors resulting in conductivity changes.

\begin{tabular}{|c|c|c|}
\hline No & Source of changes in conductivity & Enzymes \\
\hline 1 & Generation of ion groups & Amidases \\
2 & Separation of different charges & Dehydrogenases and decarboxylases \\
3 & Ion migration & Esterases \\
4 & Change in level of ion particles association & Kinases \\
5 & Change in size of charged groups & Phosphatases and sulfatases \\
\hline
\end{tabular}

However, conductometric methods have some limitations. The ratio between the signal and noise level should not be higher that $2 \%$. For this reason, the concentrations of buffer and some other ingredients, which can be added to the reaction mixture, are important. The method sensitivity drops in the presence of non-reacting ions in the solution. Buffers with low ion strength can be used, then, to measure low concentrations until the signal/noise ratio is enough. Another disadvantage of conductometry is its low specificity - it is incapable of distinguishing between reactions that can cause an artifact. The double layer capacity and the electrode polarisation during reaction can be also sources of method error. All the investigations reported have become a basis for further development of conductometric biosensors.

\section{Conductometric enzyme biosensors}

The first conductometric biosensor for urea determination has been described in [5]. It was a device consisting of a silicon substance with a pair of gold interdigitated and serpentine electrodes. The experiments were carried out in both a laboratory and clinics; the biosensor response to urea was in the range of $0.1-10 \mathrm{mM}$ in imidasole buffer, $\mathrm{pH}$ 7.5. The $\mathrm{K}_{\mathrm{M}}$ of immobilised enzyme was higher than that in the solution; the authors explained it as a result of diffusion limitation. A comparison of the data obtained by the biosensor in the laboratory with the results of conventional clinical tests showed good agreement (the correlation coefficient was higher than 0.99).

A similar conductometric biosensor has also been used as a multisensor [23]. Urease was immobilised on the surface of the first electrode pair in the gel layer; on the second pair, Lasparaginase; on the third pair, a three-enzyme system "urease-creatinase-creatininase". This sensor was used for the determination of urea, L-asparagine and creatinine, respectively. The sensor was tested with every substrate and in a multi-substance medium, the kinetic and calibration curves were determined. 


\section{Conductometric biosensors for environmental monitoring}

In Table 3 the developments in the field of conductometric enzyme biosensors for environmental monitoring during the last decades are summarized.

Table 3. Data on the development of different conductometric biosensors for environmental monitoring.

\begin{tabular}{|c|c|c|c|}
\hline № & Substance & Enzyme & References \\
\hline 1 & $\begin{array}{l}\text { Organophosphorous } \\
\text { pesticides }\end{array}$ & $\begin{array}{l}\text { Acetylcholinesterase, } \\
\text { Butyrylcholinesterase }\end{array}$ & {$[3,36,38-40,41-44,46,47]$} \\
\hline 2 & Heavy metal ions & $\begin{array}{l}\text { Urease } \\
\text { Alkaline phosphatase }\end{array}$ & $\begin{array}{l}{[37,39-42,46]} \\
{[47,48]}\end{array}$ \\
\hline 3 & Formaldehyde & Alcoholoxidase & {$[6,39,42]$} \\
\hline 4 & 4-Chlorophenol & Tyrosinase & {$[45,46]$} \\
\hline 5 & Triazine herbicides & Tyrosinase & {$[45,46,49]$} \\
\hline 6 & Carbamate pesticides & Acetylcholinesterase & [46] \\
\hline 7 & Nitrate & Nitrate reductase & {$[50,51]$} \\
\hline 8 & $\begin{array}{l}\text { Proteins as marker of } \\
\text { DOC }\end{array}$ & Proteinase K & {$[52,53]$} \\
\hline
\end{tabular}

A view of the design of the conductometric transducer (with a reference and a working electrode) and of the experimental set-up for conductometric measurements is presented in Figure 5.

Figure 5: Design of the conductometric transducer (with a reference and a working electrode) and of the experimental set-up for conductometric measurements.

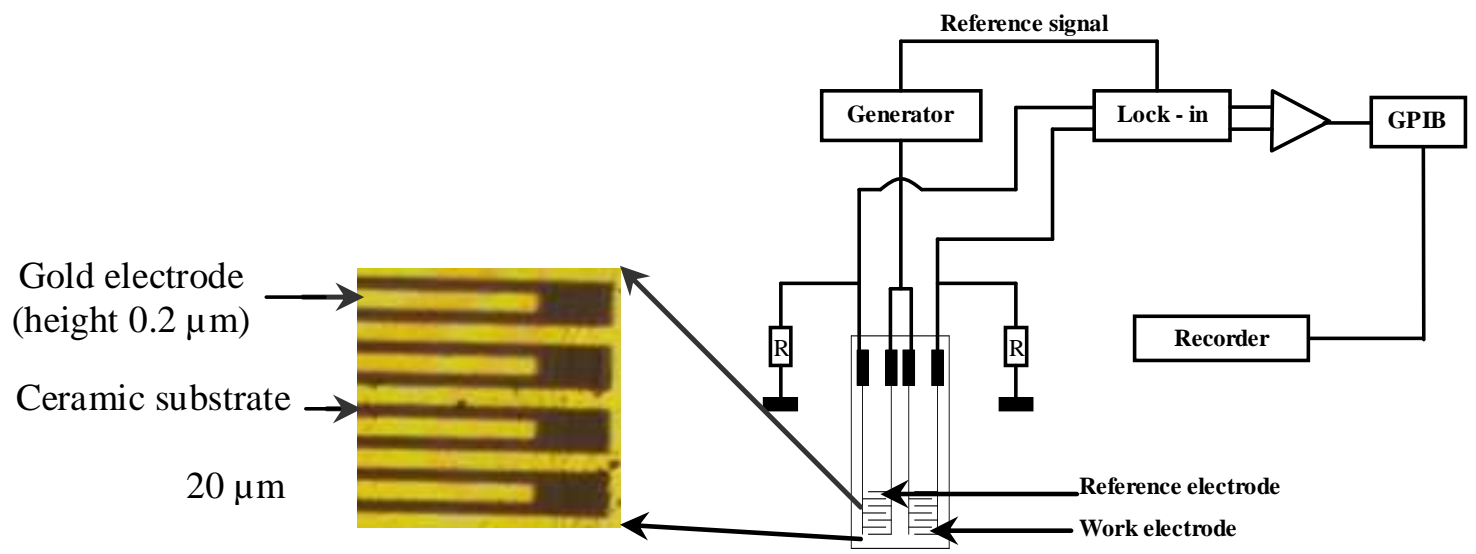

The enzyme is immobilized on the working electrode mainly through co-reticulation with BSA (bovine serum albumin) by glutaraldehyde cross-linking. On the reference electrode only BSA is coreticulated. 


\section{Conductometric biosensors for the detection of organophosphorous pesticides (based on enzyme inhibition)}

The conductometric biosensor based on inhibition analysis, first described in [36], was intended for the determination of organophosphorous pesticides. As a sensitive element, the enzymes acetyl- and butyrylcholinesterase were used. The enzymatic reaction is the following one:

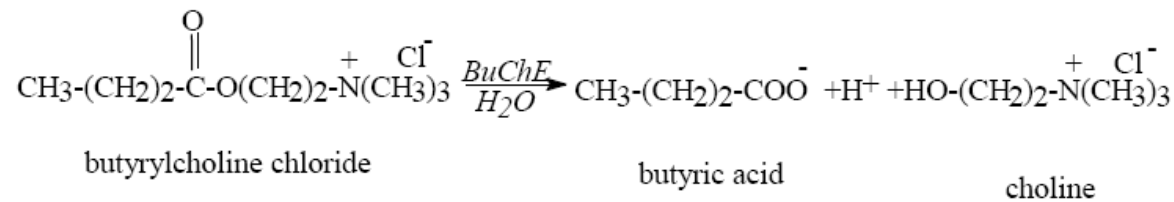

Organophosphorus compounds partly inhibit the biological activity of acylcholinesterase through phosphorylation of the serin group, according to the following reaction (example of the organophosphorus compound trichlorfon):

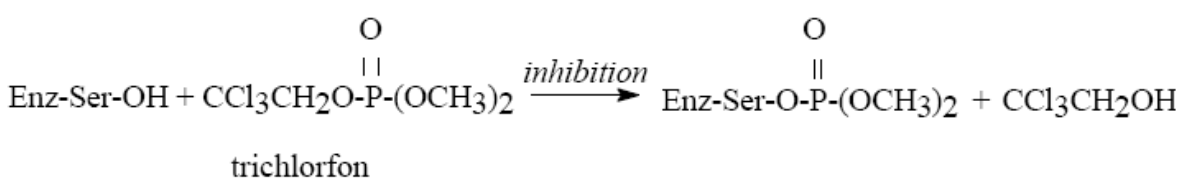

The sensor sensitivity towards different pesticides (diisopropyl fluorophosphate, paraoxon-ethyl, paraoxon-methyl, trichlorfon) was investigated and the minimal detection limits for inhibitor concentrations were: $5 \times 10^{-11} \mathrm{M}$ for diisopropyl fluorophosphate, $10^{-8} \mathrm{M}$ for paraoxon-ethyl, $5 \times 10^{-7} \mathrm{M}$ for paraoxon-methyl, and $5 \times 10^{-7} \mathrm{M}$ for trichlorfon. The dependence of biosensor response on how long the transducer was incubated in the pesticide solution was studied. The possibility of reactivating the enzyme in the membrane by means of the reactivator pyridine-2-aldoxime-methiodide, according to the following reaction, was shown.

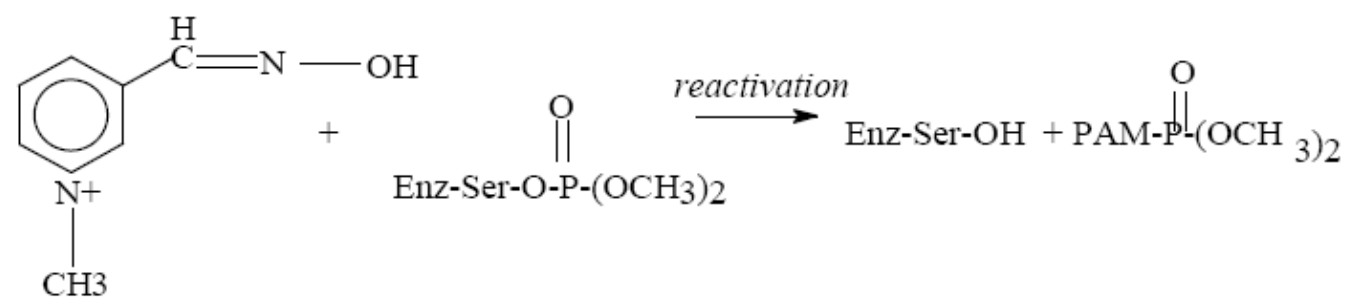

The conclusion was drawn that the described biosensors could be used for the analysis of organophosphorous pesticides in aqueous solutions.

Conductometric biosensors applied for analysing total solution toxicity at parathion-methyl photodegradation were presented in $[43,44]$. The assessment of the toxicity of the photodegradation products was performed using the percentage of inhibition of cholinesterase. The results obtained were compared with the data from traditional high-sensitive method of HPLC and from the Lumistox device (Lange, Germany) for toxicity determination. It has been found that the strongest inhibitor of 
immobilised cholinesterases was the methyl paraoxon and a strong synergistic effect of methyl parathion and methyl paraoxon was occurred. The solution toxicity was shown to increase dramatically as pesticide photodegradation began (cf. Figure 6); the toxicity remained once the parathion-methyl dissociation had been completed. Also, it is important to note that when almost all methyl parathion molecules have disappeared ( $>160 \mathrm{~min}$ ), the remaining mixtures still exhibit a relatively high toxicity, mainly imparted by methyl paraoxon. This is why commercial immunotests proposed only for the detection of methyl parathion (for example, Microwell Plate Assay EnviroLogix Inc., Portland, USA) could not be really satisfying for general toxicity test, since toxicity due to photodegradation products are not taken into account. However, the authors do not oppose the biosensor method to others, but consider it as an additional fast way for the early screening of numerous samples.

Figure 6: Photodegradation of methyl parathion showing its disappearance (1) and the evolution of methyl paraoxon (2) and the toxicity of the solution assessed by using conductometric AcChE biosensor (3).

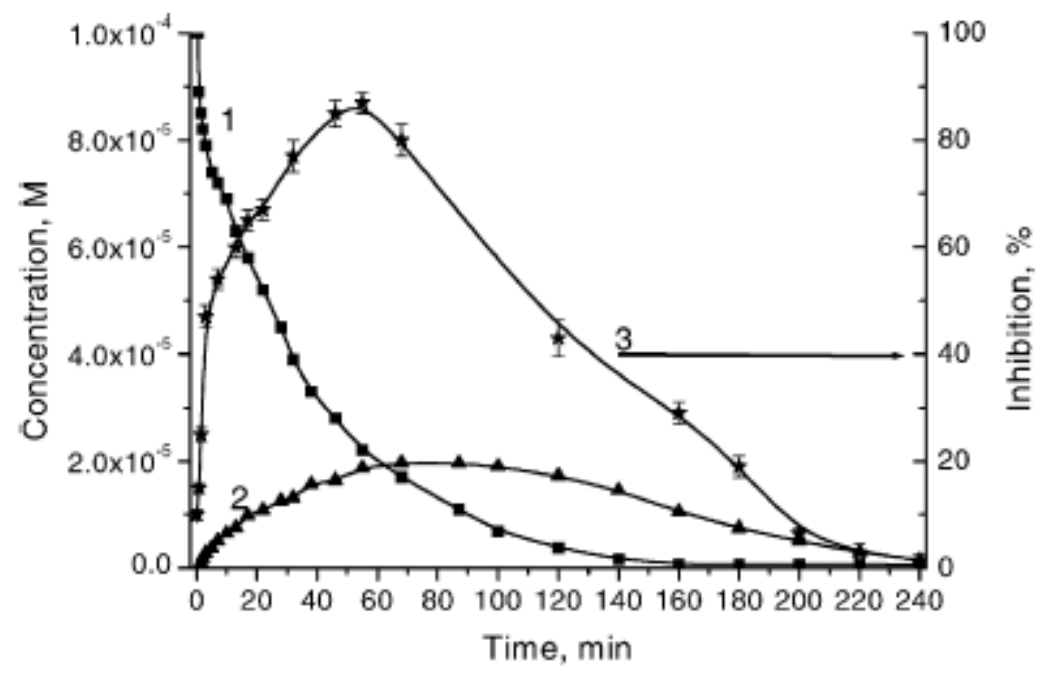

Conductometric biosensor for the detection of diuron and atrazine (based on tyrosine inhibition)

A conductometric tyrosinase biosensor for the detection of some toxic compounds including diuron, atrazine, and copper ions was developed in [45, 49]. Under the experimental conditions employed using 4-chlorophenol as enzyme substrate, and $30 \mathrm{~min}$ of contact with tyrosinase inhibitor, detection limits for diuron and atrazine were in the ppb and dynamic range of 2.3 -2330 ppb and 2.15-2150 ppb were obtained for diuron and atrazine respectively. A relative standard deviation of the output signal was estimated to be $5 \%$ and a slight drift of $1.5 \mu \mathrm{S} /$ hour was observed. The $90 \%$ of the enzyme activity was still maintained after 23 days of storage in a buffer solution at $4{ }^{\circ} \mathrm{C}$. The different samples tested were solutions containing diuron, atrazine, copper, lead and zinc ions, mixtures of copper/atrazine or copper/diuron and real water samples coming from a Vietnamese river. In the last case, classical techniques such as GC-MS or atomic absorption spectrometry were used in order to estimate exact concentration of these species in real water samples. Results have shown that such a biosensor could be used as an early warning system for the detection of these pollutants, as no matrix effect coming from 
the real sample was observed and no synergetic or antagonist effects were found for the mixture of toxic compounds. In addition, results were coherent with the content of the tyrosinase inhibitors.

\section{Conductometric biosensors for the detection of heavy metal ions (based on enzyme inhibition)}

The potential of conductometric urease biosensors for the determination of heavy metal ions was demonstrated in Ref. 37. The sensitivities of heavy metals towards urease varied as follows: $\mathrm{Hg}^{2+}>$ $\mathrm{Cu}^{2+}>\mathrm{Cd}^{2+}>\mathrm{Co}^{2+}>\mathrm{Pb}^{2+}>\mathrm{Sr}^{2+}$; reactivation of the inhibited enzyme with EDTA was shown to be possible.

\section{Conductometric biosensor for the detection of formaldehyde}

A conductometric enzyme biosensor for determination of formaldehyde in aqueous solutions has been developed using interdigitated thin-films planar electrodes and immobilised alcohol oxidase from Hansenula polymorpha was presented in [6]. The enzymatic reaction was the following:

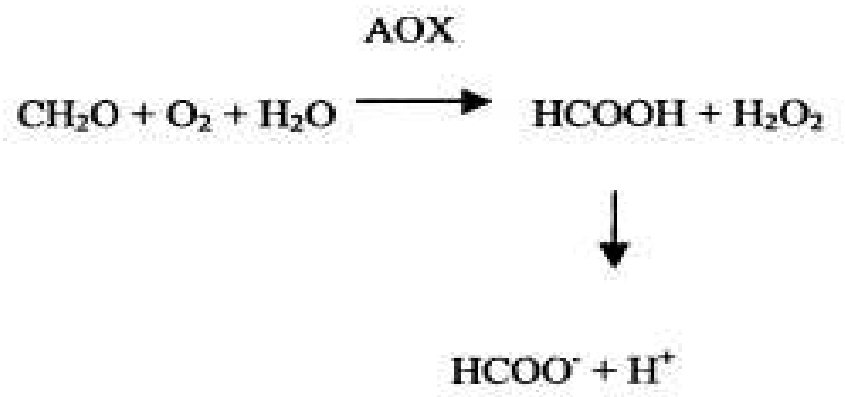

The biosensor steady-state response was reached after about $1 \mathrm{~min}$. Its dynamic range can vary from $0.05 \mathrm{mM}$ to $500 \mathrm{mM}$ formaldehyde and depends on the time of enzymatic membrane cross-linking by glutaraldehyde and on the buffer concentration used. The biosensor developed was not absolutely specific and selective. It demonstrated no response to primary alcohols and other substrates alone. Unfortunately, the response of this biosensor in mixtures of formaldehyde and methanol was decreased in comparison with the one observed for pure formaldehyde, even if no response was obtained with the interfering specie alone. The operational stability was not less than 20 hours and the relative standard deviation appeared to be about $3 \%$. Moreover, the storage stability was more than one month.

\section{Conductometric biosensor for the detection of nitrate}

A highly sensitive, fast and stable conductometric enzyme biosensor for determination of nitrate in waters was described in $[50,51]$. The conductometric electrodes were modified by methyl viologen mediator mixed with nitrate reductase from Aspergillus niger by cross-linking with glutaraldehyde in the presence of bovine serum albumin and Nafion ${ }^{\circledR}$ cation-exchange polymer, allowing retention of viologen mediator according to the following ion exchange reaction:

$$
\mathrm{MV}_{\mathrm{aq}}{ }^{2+}+2\left(\mathrm{SO}_{3}{ }^{-} \mathrm{Na}^{+}\right)_{\text {film }} \rightarrow\left[\left(\mathrm{SO}_{3}{ }^{-}\right)_{2} \mathrm{MV}^{2+}\right]_{\text {film }}+2 \mathrm{Na}_{\mathrm{aq}}{ }^{+}
$$

The enzymatic reaction for the reduction of nitrate is the following one: 


$$
\mathrm{NO}_{3}{ }^{-}+2 \mathrm{MV}^{\bullet+}+2 \mathrm{H}^{+} \rightarrow \mathrm{NO}_{2}{ }^{-}+2 \mathrm{MV}^{2+}+\mathrm{H}_{2} \mathrm{O}
$$

Linear calibration in the range of 0.02 and $0.25 \mathrm{mM}$ with detection limits of $0.005 \mathrm{mM}$ nitrate were obtained with a signal-to-noise ratio of 3 . When stored in $5 \mathrm{mM}$ phosphate buffer $(\mathrm{pH} 7.5)$ at $4^{\circ} \mathrm{C}$, the sensor showed good stability over two weeks.

\section{Conductometric biosensor for the detection of Dissolved Organic Carbon (DOC)}

A conductometric proteinase $\mathrm{K}$ biosensor for organic matter monitoring in rivers has been developed, based on a conductometric transducer [52,53]. In fact, with approximately $30 \%$ of the total organic carbon, proteins were chosen to be used as indicators of urban pollution. Proteinase $\mathrm{K}$ hydrolyzes proteins into different ionic amino-acids which results in local conductivity changes. In this work, the biosensor response using bovine serum albumin (BSA) as standard protein was optimized. A stable biosensor with a constant repeatability and a detection limit about $0.5 \mu \mathrm{g} / \mathrm{mL}$ BSA were obtained. Then, response biosensor was tested with samples of rivers water. Good correlations between conductance changes and values given by standard methods (chemical oxygen demand and protein concentration evaluated by microBCA protein assay) have been shown. Correlation coefficients of 0.89 and 0.92 were respectively obtained.

\section{Conductometric biosensor based on microalgea}

A conductometric biosensor using immobilised Chlorella vulgaris microalgae as bioreceptors was used as a bi-enzymatic biosensor in [47, 48]. Local conductivity variations caused by algae alkaline phosphatase and acetylcholinesterase activities could be detected. These two enzymes are known to be inhibited by distinct families of toxic compounds: heavy metals for alkaline phosphatase, carbamates and organophosphorous pesticides for acetylcholinesterase. The bi-enzymatic biosensors were tested to study the influence of heavy metal ions and pesticides on the corresponding enzyme. It has finally appeared that these biosensors are quite sensitive to $\mathrm{Cd}^{2+}$ and $\mathrm{Zn}^{2+}$ (limits of detection (LOD) $=10 \mathrm{ppb}$ for a 30 minute long exposure) while $\mathrm{Pb}^{2+}$ gives no significant inhibition as this ion seems to adsorb on albumin preferably. For pesticides, first experiments showed that paraoxon-methyl inhibits Chlorella vulgaris AChE contrary to parathion-methyl and carbofuran. Biosensors were then exposed to different mixtures $\left(\mathrm{Cd}^{2+} / \mathrm{Zn}^{2+}, \mathrm{Cd}^{2+} / \mathrm{MPx}\right)$ but no synergetic or antagonist effect could be observed. A good repeatability could be achieved with biosensors since the relative standard deviation did not exceed $8 \%$ while response time was 5 to 7 minutes.

\section{Conclusions}

Application of the conductometric measurement method to environmental monitoring is thoroughly examined and analysed regarding both standard conductometers and conductometric enzyme biosensors. As compared to conventional methods of analysis, the method considered is universal and features high accuracy and low labour costs. 
Conductometric biosensors also have advantages over other types of transducers. First, they may be produced through inexpensive thin-film standard technology without any reference electrode. This, along with using an optimised method of immobilisation of biological material, results in considerable decrease in both the primary cost of devices and the total price of analyses. Sure, the price of conductometric biosensor depends on quantity of sensors fabricated. In case of mass production the price of one sensor could be about 1 Euro, but such a sensor is reusable, and the total cost of analysis could be much smaller. For integrated microbiosensors it is easy to perform a differential measurement mode, thus compensating external effects and considerably increasing measurement accuracy. Also microbiosensors could be integrated and combined on the same crystal with a buffer electronic system of information processing and storage that also could decrease the primary cost of an individual device.

The data is convincing evidence of the great potential of conductometric biosensors, especially for environmental monitoring. However, it is still a novel trend in the field of biosensors, and then the development of commercial devices has a promising future, especially for microbiosensor arrays.

\section{Acknowledgments}

The authors thank DGA for supporting the publication of this review paper.

This work was partially supported by the National Academy of Sciences of Ukraine in the frame of complex scientific-technical programme "Sensor systems for medical-ecological and industrialtechnological needs" and by MASS-MOD Program.

\section{References}

1. Patnaik, P. Handbook of Environmental Analysis. Chemical pollutants in air, water, soil, and solid wastes; CRC Press Inc.: Boca Raton, USA, 1997.

2. Fernandez-Alba, A. R.; Guil, L. H.; Lopez, G. D.; Chisti, Y. Toxicity of pesticides in wastewater: a comparative assessment of rapid bioassays. Anal. Chim. Acta 2001, 426, 289-301.

3. Dzydevich, S. V.; Shul'ga, A. A.; Soldatkin, A. P.; Nyamsi Hendji, A. M.; Jaffrezic-Renault, N.; Martelet, C. Application of conductometric for sensitive detection of pesticides biosensor based on the cholinesterases. Electroanalysis 1994, 6, 752-758.

4. Shul'ga, A. A.; Soldatkin, A. P.; El'skaya, A. V.; Dzyadevich, S. V.; Strikha, V. I. Thin-film conductometric biosensor for glucose and urea determination. Biosens. Bioelectron. 1994, 9, $217-$ 223.

5. Watson, L. D.; Maynard, P.; Cullen, D. C.; Sethi, R. S.; Brettle, J.; Lowe, C. R. A microelectronic conductometric biosensor. Biosensors 1987/88, 3, 101-115.

6. Dzyadevych, S. V.; Arkhypova, V. N.; Korpan, Y. I.; El'skaya, A. V.; Soldatkin, A. P.; JaffrezicRenault, N.; Martelet, C. Conductometric formaldehyde sensitive biosensor with specifically adapted analytical characteristics. Anal. Chim. Acta 2001, 445, 47-55.

7. Lawrence, A. J.; Moores, G. R. Conductimetry in enzyme studies. Eur. J. Biochem. 1972, 24, 538546.

8. Dorokhova, E. N.; Prokhorova, G. V. Analytical chemistry. Phisical-chemical methods of analysis; Vysshaya shkola: Moscow, 1991. 
9. Gopel, W.; Jones, T. A.; Kleitz, M.; Lundstrom, J.; Seiyama, T. Conductometry. In Sensors. A Comprehensive Survey; Gopel, W.; Hesse, J.; Zemel, J. N., Eds; VCH Verlagsgesellschaft: Weinheim, 1991, Vol. 2, Part I, pp. 314-337.

10. Kell, D. B. The principles and potential of electrical admittance spectroscopy: an introduction. In Biosensors: Fundamentals and Applications; Turner, A. P. F.; Karube, I.; Wilson, G. S., Eds; Oxford University Press: Oxford, 1987, pp. 427-468.

11. Dzyadevich, S. V.; Shul'ga, A. A.; Patskovsky, S. V.; Arkhipova, V. N.; Soldatkin, A. P.; Strikha, V. I. Thin-film conductometric transducers for enzyme biosensors. Rus. J. Electrochem. 1994, 30, 887-891.

12. Olthuis, W.; Volanschi, A.; Bomer, J. G.; Bergveld, P. A new probe for measuring electrolytic conductance. Sens. Actuat. B 1993, 13-14, 230-233.

13. Olthuis, W.; Smith, A.; Van der Zalm, R. A. J.; Bergveld, P. New operational modes for the $\mathrm{Ta}_{2} \mathrm{O}_{5^{-}}$ based electrolyte conductance cell. Sens. Actuat. B 1994, 18-19, 65-68.

14. Shul'ga, A. A.; Strikha, V. I.; Dzyadevich, S. V.; Patskovsky, S. V.; Gopel, W. In Eurosensors VII; Turner, A. P. F., Ed.; Elseiver Adv. Techn.: Oxford, 1993; p. 321.

15. Weimar, U.; Gopel, W. A.C. measurements on tin oxide sensors to improve selectivities and sensitivities. Sens. Actuators B 1995, 26-27, 13-18.

16. Sheppard, N. F.; Tucker, R. C.; Wu, C. Electrical conductivity measurements using microfabricated interdigitated electrodes. Anal. Chem., 1993 65, 1199-1202.

17. Lee, W. Y.; Kim, S. R.; Kim, T. H.; Lee, K. S.; Shin, M. C.; Park, J. K. Sol-gel-derived thick-film conductometric biosensor for urea determination in serum. Anal. Chim. Acta 2000, 404, 195-203.

18. Jacobs, P.; Suls, J.; Sansen, W. Performance of a planar differential-conductivity sensor for urea. Sens. Actuat. B 1994, 20, 193-198.

19. Hintsche, R.; Moller, B.; Dransfeld, I.; Wollenberger, U.; Scheller, F.; Hoffmann, B. Chip biosensors on thin-film metal electrodes. Sens. Actuat. B 1991, 4, 287-291.

20. Trebbe, U.; Niggemann, M.; Cammann, K.; Fiaccabrino, G. C.; Koudelka-Hep, M.; Dzyadevich, S.; Shulga, O. A new calcium sensor based on ion-selective conductometric microsensors membranes and features. Fresen. J. Anal. Chem. 2001, 371, 734-739.

21. Mikkelsen, S. K.; Rechnitz, G. A. Conductometric transducers for enzyme-based biosensors. Anal. Chem. 1989, 61, 1737-1742.

22. Bilitewski, U.; Drewes, W.; Schmid, R. D. Thick film biosensors for urea. Sens. Actuat.s B 1992, 7 , 321-326.

23. Cullen, D. C.; Sethi, R. S.; Lowe, C. R. Multi-analyte miniature conductance biosensor. Anal. Chim. Acta 1990, 231, 33-40.

24. McNeil, C. J.; Athey, D.; Ball, M.; On Ho, W.; Krause, S.; Armstrong, R. D.; Wright, J. D.; Rawson, K. Electrochemical sensors bbased on impedance measurement of enzyme-catalyzed polymer dissolution: theory and application. Anal. Chem. 1995, 67, 3928-3935.

25. Sergeeva, T. A.; Lavrik, N. V.; Rachkov, A. E.; Kazantseva, Z. I.; Piletsky, S. A.; El'skaya, A. V. Hydrogen peroxide - sensitive enzyme sensor based on phtalocyanine thin film. Anal. Chim. Acta 1999, 391, 289-297. 
26. Endres, H.-E.; Drost, S. Optimization of the geometry of gas-sensitive interdigital capasitors. Sens. Actuat. B 1991, 4, 95-98.

27. Besson, C.; Vessillier, S.; Gonzales, T.; Saulnier, J.; Wallach, J. Conductimetric assay of pyroglutamyl peptidase activity. Anal. Chim. Acta 1994, 294, 305-309.

28. Dzyadevych, S. V.; Soldatkin, A. P.; Arkhypova, V. N.; Martelet, C.; Jaffrezic-Renault, N.; El'skaya, A. V. Electrochemical enzyme biosensors. IMBG Press: Kyiv, 2006.

29. On Ho, W.; Krause, S.; McNeil, C. J.; Pritchard, J. A.; Armstrong, R. D.; Athey, D.; Rawson, K. Electrochemical sensor for measurement of urea and creatinine in serum based on ac impedance measurement of enzyme-catalyzed polymer transformation. Anal. Chem. 1999, 71, 1940-1946.

30. Chin, W. T.; Kroontje, W. Conductivity method for determination of urea. Anal. Chem. 1961, 33, 1757-1760.

31. Bourrelly, P.; Bourrelly-Durand, V. Methode d'etude par conductometric differentielle de la cinetique de l'hydrolise enzymatique de l'uree. J. Chem. Phys. 1965, 65, 673-677.

32. Andreeev, V. S.; Rozengart, V. I.; Torubarov, V. A. Registration of kinetics of enzymatic reaction by high-frequency method. Ukr. Biochem. J. 1965, 37, 920-926.

33. Andreev, V. S.; Bashtanov, A. V. Differential conductometric device fo registration of physicalchemical processes. Zavodskaya laboratoriya 1968, 34, 1546-1548.

34. Hanss, M.; Rey, A. Application de la conductometrie a l'etude des reactions enzymatiques. Systeme uree-urease. Biochim. Biophys. Acta 1971, 227, 630-638.

35. Lawrence, A. J. Conductimetric enzyme assays. Eur. J. Biochem. 1971, 18, 221-225.

36. Dzyadevich, S. V.; Soldatkin, A. P.; Shul'ga, A. A.; Strikha, V. I.; El'skaya, A. V. Conductometric biosensor for organophosphorus pesticides determination. J. Anal. Chem. 1994, 49, 789-792.

37. Zhylyak, G. A.; Dzyadevich, S. V.; Korpan, Y. I.; Soldatkin, A. P.; El'skaya, A. V. Application of urease conductometric biosensor for heavy-metal ion determination. Sens. Actuat. B 1995, 24-25, 145-148.

38. Dzyadevich, S. V.; Korpan, Y. I.; Soldatkin, A. P.; Shul'ga, A. A.; Strikha, V. I.; El'skaya, A. V. Conductometric biosensor for ethanol detection based on whole yeast cells. Ukr. Biochem. J. 1993, 65, 47-54.

39. Soldatkin, A. P.; Dzyadevich, S. V.; Korpan, Y. I.; Arkhipova, V. N.; Zhylyak, G. A.; Piletsky, S. A.; Sergeeva, T. A.; Panasyuk, T. L.; El'skaya, A. V. Biosensors based on conductometric detection. Biopolymers Cell 1998, 14, 268-277.

40. Arkhypova, V. N.; Dzyadevych, S. V.; Schuvaylo, O. N.; Soldatkin, A. P.; El'skaya, A. V.; Jaffrezic-Renault, N.; Martelet, C. Concept of multibiosensors for determination of different toxic compounds based on enzyme inhibitor analysis. Biopolymers Cell 2001, 17, 70-77.

41. Arkhypova, V. N.; Dzyadevych, S. V.; Soldatkin, A. P.; El'skaya, A. V.; Jaffrezic-Renault, N.; Jaffrezic, H.; Martelet, C. Multibiosensor based on enzyme inhibition analysis for determination of different toxic substances. Talanta 2001, 55, 919-927.

42. Dzyadevych, S. V.; Arkhypova, V. N.; El'skaya, A. V.; Jaffrezic-Renault, N.; Martelet, C.; Soldatkin, A. P. Conductometric enzyme biosensors for substrates or inhibitors analysis. Curr. Top. Anal. Chem., 2001 2, 179-186. 
43. Dzyadevych, S. V.; Soldatkin, A. P.; Chovelon, J.-M. Assessment of the toxicity of parathion and its photodegradation products in water samples using conductometric enzyme biosensors. Anal. Chim. Acta, 2002 459, 33-41.

44. Dzyadevych, S. V.; Chovelon, J.-M. A comparative photodegradation studies of methyl parathion by using Lumistox test and conductometric biosensor technique. Mater. Sci. Engineer. C 2002, 21, 55-60.

45. Mai Anh, T.; Dzyadevych, S. V.; Chau Van, M.; Jaffrezic-Renault, N.; Duc Chien, N.; Chovelon, J.-M. Conductometric tyrosinase biosensor for the detection of diuron, atrazine and its main metabolites. Talanta 2004, 63, 365-370.

46. Dzyadevych, S. V.; Soldatkin, A. P.; Arkhypova, V. N.; El'skaya, A. V.; Chovelon, J.-M.; Georgiou, C.; Martelet, C.; Jaffrezic-Renault, N. Early-warning electrochemical biosensor system for the environmental monitoring based on enzyme inhibition effect. Sens. Actuat. B 2005, 55, 8187.

47. Chouteau, C.; Dzyadevych, S. V.; Durrieu, C.; Chovelon, J.-M. A bi-enzymatic whole cell conductometric biosensor for heavy metal ions and pesticides detection in water samples. Biosens. Bioelectron. 2005, 21, 273-281.

48. Chouteau, C.; Dzyadevych, S. V.; Durrieu, C.; Chovelon, J.-M. Development of novel conductometric biosensors based on immobilised whole cell Chlorella vulgaris microalgae. Biosensors Bioelectron. 2004, 19, 1089-1096.

49. Mai Anh, T.; Dzyadevych, S. V.; Prieur, N.; Nguen Duc, C.; Pham, T. D.; Jaffrezic-Renault, N.; Chovelon, J.-M. Detection of toxic compounds in real water samples using a conductometric tyrosinase biosensor. Mater. Sci. Engineer. C 2006, 26, 453-456.

50. Wang, X.; Dzyadevych, S. V.; Chovelon, J.-M.; Jaffrezic-Renault, N.; Ling, C.; Siqing, X. Development of conductometric nitrate biosensor based on Methyl viologen/Nafion ${ }^{\circledR}$ composite film. Electrochem. Comm. 2006, 8, 201-205.

51. Wang, X.; Dzyadevych, S. V.; Chovelon, J.-M.; Jaffrezic-Renault, N.; Ling, C.; Siqing, X. Conductometric nitrate biosensor based on Methyl viologen/Nafion ${ }^{\circledR} /$ Nitrate reductase interdigitated electrodes. Talanta 2006, 69, 450-455.

52. Marrakchi, M.; Dzyadevych, S. V.; Namour, Ph.; Martelet, C.; Jaffrezic-Renault, N. A novel proteinase $\mathrm{K}$ biosensor based on interdigitated conductometric electrodes for proteins determination in rivers and sewers water. Sens. Actuat. B 2005, 111-112, 390-395.

53. Marrakchi, M.; Dzyadevych, S. V.; Namour, Ph.; Martelet, C.; Jaffrezic-Renault, N. An enzyme biosensor based on gold interdigitated thin film electrodes for water quality control. Anal. Lett. 2007, 40, 1307-1316.

(C) 2008 by MDPI (http://www.mdpi.org). Reproduction is permitted for noncommercial purposes. 